УДК 316

$10.17213 / 2075-2067-2021-4-93-101$

\title{
ЭКОЛОГИЧЕСКИЙ ТУРИЗМ И ЕГО РЕСУРСНЫЙ ПОТЕНЦИАЛ В СОЦИАЛИЗАЦИИ ЦИФРОВОЙ МОЛОДЕЖИ
}

\author{
(C) 2021 г. Л. И. Саидова
}

\section{Южно-Российский государственный политехнический университет (НПИ) имени М. И. Платова, г. Новочеркасск, Россия}

Целью исследования является обоснование роли экологического туризма в сочиализаичи современной молодежи, жизненный мир которой уже не мыслится без информационных и цифровых технологий. Высокая актуальность данной проблематики объясняется как этим обстоятельством, так и связанным с ним фактором снижения здоровья молодежи, замыкающейся на своих микромирах, зачастую виртуальных и погруженных в соииальные сети в ущерб реальным практикам общения и территориальной мобильности.

Методологическую базу исследования представляют принщипы дискурсивного анализа, позволивщего выявить особенности и многообразие точек зрения и позищий относительно понятия экологического туризма, его функций и тенденций развития, а также типологического анализа, в рамках которого, включенных в обширное пространство туристских практик, экотуризм предстает как один из типов туризма.

Результаты исследования позволили обосновать точку зрения о сочиализационном потенциале экологического туризма, особенно значимого в информационную эпоху, когда циифровые технологии становятся источником дальнейшего замыкания на собственных этнокультурных мирах, сетевых коммуникациях, что ограничивает сочииализаџионный процесс, в условиях полиэтничного населения России нуждающийся в механизмах кросскультурных взаимодействий. Экологический туризм, помимо функиии сохранения экосистемы, выполняет множество иных, связанных с расширением сочиальных связей и коммуникачий в процессе туристской деятельности, знакомством с иными этнокультурными мирами, а также включением в пространство социально-полезной деятельности и становлением соииальной субъектной молодежи. Однако экологический туризм имеет и оборотную сторону. В условиях расширения и увеличения масштабов этого направления туристической деятельности растет и количество угроз окружающей среде, охранять которую призван экотуризм. На фоне этой противоречивой тенденции в развитии экологического туризма сам прочесс экологической социализации нуждается в дополнительном осмыслении с точки зрения выстраивания экологической политики в области туризма в благополучном сиенарии развития экологии и социализаџии молодых поколений.

Перспективу исследования составляет вывод о необходимости дальнейших научных изысканий в области экологического туризма как пространства социализащии российской молодежи с учетом того, что сама молодежь является активным субъектом экотуристских практик, а, значит, имеет ресурс влияния на экологическую ситуацию и вектор трансформации экотуризма как социального института. И в этом заключается ключевая перспектива социологического изучения экологического туризма как самостоятельного социиального института, включенного в институциональное пространство туризма, имеющеего общие с ним функции, а также специифические, обусловленные природой происхождения экотуризма. 
Ключевые слова: туризм; экологический туризм; цифрровая молодежь; ичифровизация; информационное общество; сочииализащия; природа; окружающзая среда.

\section{ECOLOGICAL TOURISM AND ITS RESOURCE POTENTIAL IN THE SOCIALIZATION OF DIGITAL YOUTH}

\section{(C) 2021 L. I. Saidova}

\section{Platov South Russian State Polytechnic University (NPI), Novocherkassk, Russia}

The purpose of the study is to substantiate the role of eco-tourism in the socialization of modern youth, whose life world can no longer be imagined without information and digital technologies. The high relevance of this issue is explained both by this circumstance and by the associated factor of reducing the health of young people who are locked in their microcosms, often virtual and immersed in social networks to the detriment of real communication practices and territorial mobility.

The methodological basis of the research is represented by the principles of discursive analysis, which made it possible to identify the features and diversity of points of view and positions regarding the concept of ecological tourism, its functions and development trends, as well as typological analysis, in which ecotourism appears as one of the types of tourism included in the vast space of tourist practices.

The results of the study allowed us to substantiate the point of view about the socialization potential of eco-tourism, which is especially significant in the information age, when digital technologies become a source of further closure on their own ethno-cultural worlds, network communications, which limits the socialization process, which needs mechanisms of cross-cultural interactions in the conditions of the multi-ethnic population of Russia. Ecological tourism, in addition to the function of preserving the ecosystem, performs many other functions related to the expansion of social ties and communications in the process of tourist activity, acquaintance with other ethno-cultural worlds, as well as inclusion in the space of socially useful activities and the formation of social subjective youth. However, eco-tourism has a downside. In the context of the expansion and increase in the scale of this area of tourist activity, the number of threats to the environment, which ecotourism is designed to protect, is also growing. Against the background of this contradictory trend in the development of ecological tourism, the process of ecological socialization itself needs additional reflection from the point of view of building an environmental policy in the field of tourism in a successful scenario for the development of ecology and socialization of young generations.

The perspective of the study is the conclusion about the need for further scientific research in the field of ecotourism as a space for socialization of Russian youth, taking into account the fact that young people themselves are an active subject of ecotourism practices, and, therefore, have a resource of influence on the environmental situation and the vector of transformation of ecotourism as a social institution. And this is the key perspective of the sociological study of ecotourism as an independent social institution included in the institutional space of tourism, having common functions with it, as well as specific ones due to the nature of the origin of ecotourism.

Key words: tourism; ecological tourism; digital youth; digitalization; information society; socialization; nature; environment. 
Введение. В современном обществе наблюдается динамичное развитие туризма, который для многих стран становится ключевым направлением экономического развития. Для России, обладающей колоссальными природными и историко-культурными ресурсами, данная отрасль экономики также является значимой, что и определяет вектор государственной политики, ориентированной на долговременное развитие туризма как магистральное в социально-экономической динамике российского государства [1]. Туризм в России развивается достаточно активно, чему способствует ряд факторов, связанных, прежде всего, с обширной и многообразной территорией страны с богатейшим природным и этнокультурным ландшафтом, величайшим историческим наследием, а также осознанием важности развития внутреннего туризма как фактора развития межкультурной коммуникации и закрепления межэтнических и межрегиональных связей полиэтничного российского населения. Последнее обстоятельство представляет особую важность для российского общества, испытывающего острый дефицит культуры межэтнического общения [2].

Сеть туристских практик стремительно развивается не только в логике традиционных видов туризма (спортивного, развлекательного, познавательного), но и новых его направлений, рождаемых самой эпохой с ее информационной динамикой развития и переходом к цифровым технологиям, значительно изменившим облик современного мира и человека [3], а также ключевых институтов социализации и, прежде всего, института образования [4-6]. Этот новый цифровой мир, имеющий преимущества по сравнению с предыдущими историческими этапами развития мирового сообщества, несет с собой множество рисков, связанных с устоявшимися принципами развития рыночной экономики, и ситуация пандемии коронавируса обозначила критический характер такого формата социальноэкономического развития и социокультурной траектории социума в целом [7].

Многие страны, относящиеся к ряду экономически развитых, оказались в ситуации глубокого кризиса, не столько экономического, сколько социального, связанного с переосмыслением самой парадигмы социокуль- турного развития в логике рыночно ориентированной экономики. В этой связи сформировалось понимание того, что необходимо изменить социально-экономическое устройство с отказом от принципов свободного рынка как решающего все проблемы и переходом к обществу нового формата — «социальноэкологическому рыночному обществу» (термин член-корреспондента РАН Р. Гринберга), в основе которого общество «с человеческим лицом» [8].

И в этой «экологической» парадигме общественного развития естественным образом на передний план выходит экологический туризм как ориентированный на сохранение целостности экосистемы [9].

Как известно, в туристских практиках активно принимает участие молодежь как наиболее мобильная, стремящаяся к познанию всего нового, открытая миру и готовая к апробации новых социальных практик, в том числе и туристских. Предпочтения молодежи в туризме достаточно многообразны. Если говорить о российской молодежи, то традиционную активность она проявляет в области спортивного туризма в самых различных его проявлениях и видах с упором на экстремальные (скалолазание, альпинизм, горный туризм, рафтинг и т.д.), но и туристское направление, связанное со знакомством с природными достопримечательностями и культурным достоянием России, также привлекает внимание молодых граждан страны [10]. В отношении экологического туризма, который с каждым годом наращивает свой потенциал развития за счет ежегодного увеличения количества экотуристов на 7-20\% (в разных странах динамика отличается) [11], можно сказать, что этот вид туризма постепенно становится зоной притяжения молодежи. Исследователи даже отмечают, что экологический туризм наиболее востребован среди представителей молодого поколения [12].

В любом случае, независимо от вида туризма, от функций, которые он выполняет, а они самые разнообразные - от оздоровления, достижения спортивных результатов до расширения кругозора и познания родного края, его культуры и истории, а также национальных культур других регионов и стран, туризм в целом можно и следует рассматривать как пространство социализации личности. 
Экологический туризм в фокусе научной рефлексии. Понятие экологического туризма является одним из тех, которые обросли многочисленными дефинициями, восприятиями, научными коннотациями. Ученые насчитывают более 100 определений данного понятия, указывая, что первое из них было дано Д. Хетзером, который понимал под ним «вид деятельности, основанный на естественных и археологических ресурсах, например, наблюдение за птицами и представителями дикой природы, посещение живописных территорий, пещер, мест находок ископаемых видов, археологических объектов, вредных и болотных территорий, районов редких или вымирающих видов флоры и фауны» [9, с. 2193].

Сложности определения понятийных границ экологического туризма связаны с тем, что само по себе данное понятие достаточно общее, вмещающее в себя все возможное разнообразие туристских практик, связанных с познанием природы, ее сохранением и защитой [12], а потому и определений феномену дано большое количество. В одних, как мы уже указали, акцент делается на посещении мест дикой нетронутой природы, в других — на деятельности по охране природы, сохранении экосистемы. Есть определения, в которых эти акценты объединены в единую дефиницию экологического туризма. Так, согласно определению В.В. Лапочкиной, Н. В. Косаревой, Т. А. Адашовой, экологический туризм - «это форма природоориентированного туризма, осуществляемая с целью познания дикой природы и культуры дестинации, не нарушающая целостности экосистемы, призванная внести вклад в сохранение природных ресурсов, охрану окружающей среды и социально-экономическое развитие туристской территории» [13].

Проанализировав ряд дефиниций российских и зарубежных исследователей, Д.С. Богатырева пришла к выводу, что экологический туризм следует рассматривать как «природоориентированный вид туризма, который призван гармонизировать отношения между человеком и окружающей средой, важной функцией которого является экологическое просвещение и воспитание» $[14$, c. 22]. Как видим, в данном определении совмещены акценты, связанные с охра- ной природы и просвещенческой функцией экологического туризма.

Иной подход к изучению экологического туризма, основанный на институциональной парадигме, предлагает П.В. Жуков. В его концептуальном ракурсе экотуризм - подсистема социального института туризма, представляющая собой «социальное образование, в котором развиваются социальные отношения и взаимодействия с участием субъектных носителей социальных отношений (экотуристы, турфирмы, особо охраняемые природные территории (далее ООПТ))» [15, с. 9]. В своей институциональной ипостаси экотуризм призван выполнять разнообразные социальные функции и удовлетворять групповые и индивидуальные потребности социально-экологического порядка. Само возникновение данного вида туризма как подсистемы института туризма Жуков связывает с разрушительным эффектом туристских практик по мере развития туристической отрасли. Туристическая деятельность, приносящая крупные доходы, способствующая удовлетворению самых различных видов человеческих потребностей приключенческого, познавательного, коммуникативного и иного порядка, является одновременно и фактором деградации природной среды, разрушения целостности и уникальности природных ландшафтов и экосистемы в целом, так как высокая динамика туристских потоков способствует возрастанию антропогенной нагрузки и, соответственно, отрицательных последствий туристской деятельности. И именно на стыке противоречивых последствий развития института туризма как социума, важного и необходимого для социокультурной динамики, но несущего разрушительные явления для экосистемы, рождается экологический туризм, ставший своего рода ответом развитых стран на негативные последствия от массового туризма к концу XX века [15].

О разрушительных последствиях самого экологического туризма пишут такие исследователи, как В.С. Плотникова, А.В. Васильева. Проблемы и угрозы окружающей среде, связанные с экологическим туризмом, эти ученые связывают с несовершенной политикой тех структур и организаций, которые призваны осуществлять надзор и контроль на природных территориях, с критическим 
ростом рекреационной нагрузки на определенные природные территории, находящиеся в зоне особой охраны, а также с расхождением между принципами экологического туризма и реализуемыми в ходе экологических туров практиками [9].

В обозначенной ситуации тематика, связанная с экологическим туризмом, привлекает все большее количество исследователей, изучающих ее под собственным углом зрения в соответствии с поставленными задачами. Наша задача сводится к обоснованию социализационной миссии экологического туризма как ключевой в современном цифровом мире, в котором рождается и обретает субъектность «цифровая» молодежь.

Социализационная миссия экологического туризма в цифровую эпоху: молодежный формат. Безусловно, туризм как отрасль экономики ориентирован, прежде всего, на извлечение прибыли, на ее увеличение, но как социальный институт туризм призван выполнять множество функций. Наиболее значимая из них связана с социокультурной целью, которая достигается за счет трансляции через знакомство с культурным наследием общества ценностей согласия, консолидации, межэтнической гармонии, международного сотрудничества. Справедливым можно считать мнение специалистов, полагающих, что туристское пространство есть «зона общения, сфера раскрытия способностей и реализации потребности в самовыражении и признании» $[16$, с. 48$]$. Именно в этом и заключается институциональная суть туризма как пространства социализации. В этом его социализационная миссия и значимость для воспитания молодых поколений, особенно современных, цифровых, рожденных в эпоху господства информации и цифровых технологий, без которых мир уже немыслим, хоть он и несет массу угроз современной человеческой цивилизации, прежде всего, в контексте цифровизации самого человека [17].

Социализационная миссия туризма наиболее выражена в таком виде туризма, как экологический, поскольку само его происхождение и распространение, как отмечают исследователи, связано с тем, что человечество осознало губительное и глобальное по своим последствиям влияние своей ин- дустриальной деятельности, а потому экологический туризм зачастую еще называют природо-ориентированным, социально-ответственным [13].

Растущая популярность экотуризма, на долю которого по некоторым данным уже приходится более 10-20\% прибыли от всего туристского рынка [18], можно объяснить тем, что он представляет возможность побывать в экологически чистых уголках природы, получить эстетическое удовольствие, набраться физических и духовных сил, почувствовать гармонию с природой, что особенно важно в мире, стремительно утрачивающем связи с природой и замыкающемся не только в пространстве городов, но информационных технологий.

Для молодежи, погруженной в социальные сети и проводящей больше времени за компьютером, чем на природе, экотуризм крайне важен, поскольку восприятие природы в этом виде туризма способствует формированию особого типа сознания, ориентированного не на загрязнение окружающей среды, не на разрушение природного ландшафта, а на его сохранение как фундамента гармоничного развития личности и сосуществования человека с окружающей средой в гармонии [19].

Современное молодое поколение социализируется в среде, далекой от принципов и норм здоровьесбережения. По праву называемая молодежью экранной, цифровой, компьютерной, эта среда с самого рождения связана со всевозможными средствами компьютерной и иной информационной техники, что формирует специфический фон социализации и самой реальности как сверхтехнологизированной, антропотехногенной. Указанные социальные факторы становятся определяющими в формировании здоровья подростков и молодежи [20], а многочисленные данные о снижении здоровья в молодежной среде современного российского общества говорят о том, что новая цифровая реальность и информационная среда социализации молодежи рискогенна по своей сути, что она несет риск здоровью молодежи.

В указанных обстоятельствах вопрос о создании здоровьесберегающей среды для молодежи не носит праздный характер, а приобретает чрезвычайную остроту [21]. 
Необходимы условия, при которых цифровое поколение молодежи сможет развиваться без рисков для здоровья. Такая среда должна сформироваться в противовес техногенной, чтобы создать необходимый баланс природного и техногенного. Для этого необходимо использовать потенциал тех видов деятельности, которые позволяют оторваться от экранов мониторов, увидеть мир не сквозь призму экранных сюжетов, а собственными глазами. И экологический туризм имеет все ресурсы для создания таких условий.

Реализуя экотуристские практики, молодежь имеет возможность не только познать окружающий мир, оценить всю красоту дикой природы, но и познать себя, понять свое место в этой экосистеме. Экологический туризм позволяет стать взрослее, сознательнее, более ответственно относиться к окружающей среде, к своей роли в обществе, поскольку активное включение молодых граждан в экотуристские практики способствуют столь же активному включению и в социальную жизнь, в решение социально значимых задач.

Таким образом, экологический туризм как агент социализации способствует формированию социальной субъектности молодежи, ее интеграции в социальные отношения и обретению статуса полноценного социального актора, включенного в систему социальных связей и социально-полезной деятельности.

Заключение. Экологический туризм как предметное пространство научной и социологической рефлексии нуждается в глубокой научной разработке, поскольку он обладает значительным ресурсом решения актуальных социальных проблем российского общества через реализацию многочисленных функций и прежде всего социализационной.

В данном тематической направлении уже работают исследователи, стремящиеся создать теоретические основы для изучения этого вида туризма, а также его роли в развитии молодежи. Однако высокая динамика цифрового общества не оставляет сомнений в том, что любая сфера социальной жизни, любые социальные практики, в том числе и туристские, нуждаются в постоянном научном мониторинге, постоянном внимании в контексте отслеживания новых тенденций и перспектив в их развитии.

Полагаем, интерес к экологическому туризму, обозначившийся в российской социологической науке, еще долго будет предметом научного дискурса и эмпирических практик, так как экотуризм стремительно расширяется во всем мире и в России в том числе, обозначая большие перспективы дальнейшей динамики в мире, развивающемся по технократической траектории. Более того, рожденный в ответ на вызовы техногенной эпохи в целях защитить природные территории, приблизить человека к природе, создать его экологическое сознание, он сам становится угрозой экосистеме по мере роста экотуристов и развития экотуристической отрасли, что свидетельствует о противоречивом формате становления и развития экотуризма как подсистемы института туризма. Дальнейшее развитие экотуризма в России должно быть подчинено логике сохранения уникальной природы российских регионов, а также реализации его социализационной миссии через приобщение к целостной и не разрушенной человеком природе.

\section{Литература}

1. Стратегия развития туризма в Российской Федерации на период до 2035 года (утверждена Распоряжением Правительства Российской Федерации от 20 сентября 2019 года №2129-p) [Электронный ресурс]. - Peжим доступа: https://tourism.gov.ru/contents/ documenty/strategii/strategiya-razvitiya-turizmav-rossiyskoy-federatsii-v-period-do-2035-goda.

2. Мустафаев Ф.М. Факторы разрушения культуры межнационального общения в современном полиэтничном пространстве российского общества // Гуманитарные и социальные науки. — 2014. — №3. - C. 113-123.

3. Процессы цифровизации в современном социуме: тенденции и перспективы развития: сборник докладов Всероссийской научно-практической конференции с международным участием (Елец, 27 ноября 2019 г.)/ под ред. И.В. Дарда и др. - М.: Редакционно-издательский дом Российского нового университета, 2019.

4. Верещагина А. В., Нечипуренко В.Н., Самыгин С. И. Ценностный кризис современ- 
ного образования в исторической проекции и динамике модернизации его парадигмальных оснований в условиях вызовов информационной эпохи // Контекст и рефлексия: философия о мире и человеке. - 2016. №2. - C. 74-91.

5. Воденко К. В., Боровая Л. В., Ефимов А.В. Российское образование в условиях глобальной информатизации и цифровизации: социально-философский дискурс // Гуманитарий Юга России. - 2020. - Т. 9. №3. - С. 36-44.

6. Лубский А. В., Ковалев В. В. От «онлайнизации» высшей школы к онлайн-образованию // Гуманитарий Юга России. - 2020. T. 9. 一 №2. - С. 33-50.

7. Волков Ю.Г., Курбатов В. И. Глобальная социология пандемии: отечественные и зарубежные сценарии и тренды послекоронавирусного мира // Гуманитарий Юга России. - 2020. - Т. 9. - №2. - С. 17-32.

8. Постпандемический мир и Россия: новая реальность [Электронный ресурс]. Режим доступа: https://www.interfax.ru/ interview/708800.

9. Плотникова В. С., Васильева А.В. Рекреационная емкость как организационноэкономический инструмент развития экологического туризма на особо охраняемой природной территории // Экономические отношения. - 2019. - Т. 9. - №3. - С. 21912202. — DOI: 10.18334/eo.9.3.40950.

10. Булганина С. В., Ананьева К. В., Тюмина Н. С., Шутова Ю. Г. Маркетинговое исследование предпочтений молодежи в области туризма [Электронный ресурс] // Интернетжурнал «Науковедение». - 2016. - Т. 8. №4. - Режим доступа: http://naukovedenie.ru/ PDF/06EVN416.pdf.

11. Афанасьев О.Е., Афанасьева А.В. Концепт «экологического туризма» в мировой и российской практике: компаративный анализ и кейсы // Современные проблемы сервиса и туризма. - 2017. — №4. - C. 7-26. — DOI: 10.22412/1995-0411-2017-11-4-7-25.

12. Поуесов А.В., Виницкая А. В. Экологический туризм в досуге молодежи [Электронный ресурс]. - Режим доступа: http:// www.tsutmb.ru/nauka/internet-konferencii/6visheslovatskie-chtenia/pouesov.pdf.

13. Лапочкина В.В. Косарева Н.В., Адашова T.A. Экологический туризм в России: тенденции развития [Электронный ресурс]// Международный научно-исследовательский журнал. - 2016. - №5 (47). - Ч. 1. C. 100-105. - Режим доступа: https://researchjournal.org/economical/ekologicheskij-turizmv-rossii-tendencii-razvitiya/.

14. Богатырева Д. С. Феномен экологического туризма как мейнстрим современности // Сервис в России и за рубежом. 2015. - №4. - С. 16-26.

15. Жуков П. В. Экотуризм как подсистема социального института туризма // Сетевой журнал «Научный результат». Серия: Технологии бизнеса и сервиса. — 2016. - Т. 2. №1 (7). - C. 8-11. - DOI: 10.18413/24089346-2016-2-1-8-11.

16. Степановский Е. П., Скляров А.В. Социализация в туристском пространстве // Научный вестник ЮИМ. — 2015. — №4. C. 48-52.

17. Цифровизация человека: влияние цифровых технологий на общество [Электронный pecypc]. - Режим доступа: https://mentamore. $\mathrm{com} /$ socium/cifrovizaciya-cheloveka.html.

18. Щербакова E. A. Экологический туризм как приоритетное направление культивирования здорового образа жизни среди студенческой молодежи [Электронный pecypc]. - Режим доступа: https://www. sgu.ru/sites/default/files/conf/files/2017-03/ shcherbakova e.a. idpo 2017.pdf.

19. Крайнов $\bar{A}$.Л. Экологическое сознание: сущность и социально-исторические феномены: автореф. ... дис. канд. филос. наук. - Саратов, 2001. - 17 с.

20. Журавлева И.В., Лакомова Н. В. Социальная обусловленность здоровья подростков во временном аспекте // Социологическая наука и социальная практика. - 2019. №2 (26). - С. 132-151.

21. Бойченко Я.Б. Здоровьесбережение современной молодежи: монография. - Х.: Издательство Иванченко И. С., 2013. - 195 с.

\section{References}

1. Strategija razvitija turizma v Rossijskoj Federacii na period do 2035 goda (utverzhdena Rasporjazheniem Pravitel'stva Rossijskoj Federacii ot 20 sentjabrja 2019 goda №2129-r) [The strategy of tourism development in the Russian Federation for the period up to 2035 (approved 
by the Decree of the Government of the Russian Federation No. 2129-r of September 20, 2019)] [Jelektronnyj resurs]. — URL: https://tourism. gov.ru/contents/documenty/strategii/strategiyarazvitiya-turizma-v-rossiyskoy-federatsii-v-period-do-2035-goda.

2. Mustafaev F.M. Faktory razrushenija kul'tury mezhnacional'nogo obshhenija v sovremennom polijetnichnom prostranstve rossijskogo obshhestva [Factors of the destruction of the culture of interethnic communication in the modern multi-ethnic space of Russian society]// Gumanitarnye i social'nye nauki [Humanities and social Sciences]. - 2014. — №3. - Pp. 113-123.

3. Processy cifrovizacii v sovremennom sociume: tendencii i perspektivy razvitija: sbornik dokladov Vserossijskoj nauchno-prakticheskoj konferencii s mezhdunarodnym uchastiem (Elec, 27 nojabrja 2019 g.) [The process of digitalization in the modern society: trends and prospects: collection of reports of all-Russian scientificpractical conference with international participation (Elec, 27 Nov. 2019)] / pod red. I. V. Darda i dr. [In I.V. Darda et al. (eds.)]. - Moscow: Redakcionno-izdatel'skij dom Rossijskogo novogo universiteta, 2019.

4. Vereshhagina A.V., Nechipurenko V.N., Samygin S.I. Cennostnyj krizis sovremennogo obrazovanija $\mathrm{v}$ istoricheskoj proekcii i dinamike modernizacii ego paradigmal'nyh osnovanij $\mathrm{v}$ uslovijah vyzovov informacionnoj jepohi [Value crisis of modern education in the historical projection and dynamics of the modernization paradigm bases in the context of the challenges of the information age] // Kontekst i refleksija: filosofija o mire i cheloveke [The context and reflection: philosophy of the world and man]. — 2016. №2. - Pp. 74-91.

5. Vodenko K. V., Borovaja L. V., Efimov A. V. Rossijskoe obrazovanie v uslovijah global'noj informatizacii i cifrovizacii: social'no-filosofskij diskurs [Russian education in the conditions of global informatization and digitalization: sociophilosophical discourse]// Gumanitarij Juga Rossii [Humanities of the South of Russia]. 2020. - Vol. 9. - №3. - Pp. 36-44.

6. Lubskij A. V., Kovalev V.V. Ot «onlajnizacii» vysshej shkoly k onlajn-obrazovaniju [From «Onlinization» of higher school to online education] // Gumanitarij Juga Rossii [Humanities of the South of Russia]. — 2020. — Vol. 9. №2. - Pp. 33-50.
7. Volkov Ju. G., Kurbatov V.I. Global'naja sociologija pandemii: otechestvennye i zarubezhnye scenarii i trendy poslekoronavirusnogo mira [Global sociology of the pandemic: domestic and foreign scenarios and trends of the postcoronavirus world] // Gumanitarij Juga Rossii [Humanities of the South of Russia]. - 2020. Vol. 9. - №2. - Pp. 17-32.

8. Postpandemicheskij mir i Rossija: novaja real'nost' [The post-pandemic world and Russia: new reality] [Jelektronnyj resurs]. — URL: https://www.interfax.ru/interview/708800.

9. Plotnikova V.S., Vasil'eva A.V. Rekreacionnaja emkost' kak organizacionno-jekonomicheskij instrument razvitija jekologicheskogo turizma na osobo ohranjaemoj prirodnoj territorii [Recreational capacity as an organizational and economic tool for the development of ecological tourism in a specially protected natural area]// Jekonomicheskie otnoshenija [Economic relations]. — 2019. — Vol. 9. — №3. - Pp. 21912202. — DOI: 10.18334/eo.9.3.40950.

10. Bulganina S.V., Anan'eva K. V., Tjumina N.S., Shutova Ju. G. Marketingovoe issledovanie predpochtenij molodezhi $\mathrm{v}$ oblasti turizma [Marketing research of youth preferences in the field of tourism] [Jelektronnyj resurs]// Internet-zhurnal «Naukovedenie» [Online magazine «Science Studies»]. — 2016. — Vol.8. - №4. — URL: http://naukovedenie.ru/ PDF/06EVN416.pdf.

11. Afanas'ev O. E., Afanas'eva A. V. Koncept «jekologicheskogo turizma» $\mathrm{V}$ mirovoj $\mathrm{i}$ rossijskoj praktike: komparativnyj analiz i kejsy [The concept of «ecological tourism» in world and Russian practice: comparative analysis and cases] // Sovremennye problemy servisa i turizma [Modern problems of service and tourism]. - 2017. - №4. - Pp. 7-26. - DOI: 10.22412/1995-0411-2017-11-4-7-25.

12. Pouesov A. V., Vinickaja A.V. Jekologicheskij turizm v dosuge molodezhi [Ecological tourism in the leisure of youth] [Jelektronnyj resurs]. - URL: http://www.tsutmb.ru/nauka/ internet-konferencii/6-visheslovatskie-chtenia/ pouesov.pdf.

13. Lapochkina V.V. Kosareva N. V., Adashova T.A. Jekologicheskij turizm v Rossii: tendencii razvitija [Ecological tourism in Russia: development trends] [Jelektronnyj resurs] // Mezhdunarodnyj nauchno-issledovatel'skij zhurnal [International Scientific Research Journal]. — 2016. - 
№5 (47). — Part 1. - Pp. 100-105. — URL: https://research-journal.org/economical/ekologicheskij-turizm-v-rossii-tendencii-razvitiya/.

14. Bogatyreva D.S. Fenomen jekologicheskogo turizma kak mejnstrim sovremennosti [The phenomenon of ecological tourism as the mainstream of modernity] // Servis v Rossii i za rubezhom [Service in Russia and abroad]. 2015. — №4. - Pp. 16-26.

15. ZhukovP.V. Jekoturizm kak podsistema social'nogo instituta turizma [Ecotourism as a subsystem of the social institute of tourism] // Setevoj zhurnal «Nauchnyj rezul'tat». Serija: Tehnologii biznesa i servisa [Online magazine «Scientific result». The series :Technologies of business and service]. - 2016. - Vol. 2. — №1 (7). — Pp. 8-11. DOI: 10.18413 /2408-9346-2016-2-1-8-11.

16. Stepanovskij E.P., Skljarov A. V. Socializacija $\mathrm{v}$ turistskom prostranstve [Socialization in the tourist space] // Nauchnyj vestnik JuIM [Scientific Bulletin of the YUIM]. — 2015. №4. - Pp. 48-52.

17. Cifrovizacija cheloveka: vlijanie cifrovyh tehnologij na obshhestvo [Human digitalization: the impact of digital technologies on society] [Jelektronnyj resurs]. — URL: https://mentamore. $\mathrm{com} /$ socium/cifrovizaciya-cheloveka.html.
18. Shherbakova E.A. Jekologicheskij turizm kak prioritetnoe napravlenie kul'tivirovanija zdorovogo obraza zhizni sredi studencheskoj molodezhi [Ecological tourism as a priority direction of cultivating a healthy lifestyle among students] [Jelektronnyj resurs]. — URL: https:// www.sgu.ru/sites/default/files/conf/files/2017-03/ shcherbakova_e.a._idpo_2017.pdf.

19. Krajnov A.L. Jekologicheskoe soznanie: sushhnost' i social'no-istoricheskie fenomeny: avtoref. ... dis. kand. filos. nauk [Ecological consciousness: the essence and socio-historical phenomena: Ph. D. (Phylosophy) Thesis]. Saratov, 2001. - $17 \mathrm{p}$.

20. Zhuravleva I. V., Lakomova N.V. Social'naja obuslovlennost' zdorov'ja podrostkov vo vremennom aspekte [Social conditionality of adolescent health in a temporary aspect] // Sociologicheskaja nauka i social'naja praktika [Sociological science and social practice]. — 2019. №2 (26). - Pp. 132-151.

21. Bojchenko Ja. B. Zdorov'esberezhenie sovremennoj molodezhi: monografija [Health care of modern youth: a monograph]. - Kharkiv: Izdatel'stvo Ivanchenko I. S., 2013. - 195 p.

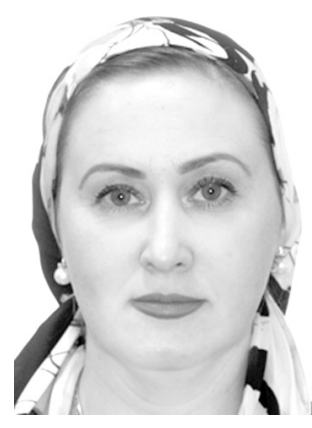

Саидова Липа Исаевна - аспирант Южно-Российского государственного политехнического университета (НПИ) имени М.И. Платова, старший преподаватель кафедры туризма и индустрии гостеприимства Чеченского государственного университета.

Saidova Lipa Isaevna - Postgraduate Student, Platov South Russian State Polytechnic University (NPI), a Senior Lecturer at the Department of Tourism and Hospitality Industry of the Chechen State University.

346428, г. Новочеркасск, ул. Просвещения, 132 132 Prosveshcheniya st., 346428, Novocherkassk, Russia E-mail: lipa-ch1enti@mail.ru 